\title{
A Modified Intrascleral Intraocular Lens Fixation Technique Using 27-Gauge Blunted Needles with Fewer Intraocular Manipulations
}

\author{
Kazuya Morino $\mathbb{D}$, Yuto Iida $(\mathbb{D}$, and Masayuki Akimoto \\ Ophthalmology, Osaka Red Cross Hospital, 5-30 Fudegasaki-cho, Tennoji-ku, Osaka 543-8555, Japan \\ Correspondence should be addressed to Masayuki Akimoto; masayuki@akimoto3.com
}

Received 25 May 2021; Revised 22 October 2021; Accepted 2 November 2021; Published 20 November 2021

Academic Editor: Su-Ho Lim

Copyright (c) 2021 Kazuya Morino et al. This is an open access article distributed under the Creative Commons Attribution License, which permits unrestricted use, distribution, and reproduction in any medium, provided the original work is properly cited.

\begin{abstract}
A new method for intraocular lens (IOL) fixation in the scleral tunnel using two common 27G blunted needles and an ultrathin $30 \mathrm{G}$ needle with fewer intraocular manipulations was developed. Half-depth scleral flaps were prepared, and vertically angled sclerotomies were performed under each scleral flap, $2 \mathrm{~mm}$ from the limbs with a 20G microblade or a 26G needle. Two bent 27G blunted needles connected the sclerotomy and corneoscleral incisions. One haptic was inserted into this bent $27 \mathrm{G}$ blunted needle extraocularly and extruded through the sclerotomy site. Each haptic was inserted into the lumen of the preplaced ultrathin $30 \mathrm{G}$ needle and buried into the scleral tunnel. In this retrospective study, we reviewed the outcomes of this new technique in patients with at least 3 months' follow-up data. Iris capture of the IOL was not observed in any case, and IOL repositioning was not performed either. Astigmatism induced by intraocular aberration was almost as same as that with other methods. Our technique can be performed in any operation room without any extra instruments. This trial is registered with UMIN000044350.
\end{abstract}

\section{Introduction}

Implantation of an intraocular lens (IOL) in the absence of capsular support has been accomplished by using an anterior chamber (AC) IOL [1-4], iris-fixed IOL [5-7], and intrascleral fixed posterior chamber (PC) IOL [8-26]. In recent years, sutureless techniques for intrascleral fixation of IOL are gaining popularity among ophthalmic surgeons because of lesser incidence of corneal endothelial cell loss, glaucoma, and peripheral anterior synechiae [1-4], despite the invention of new techniques of retropupillary iris-fixed IOL fixation over the past few years [5-7]. Some studies have shown that corneal endothelial cell density does not significantly change between implantation in $\mathrm{AC}$ and retropupillary regions. [6, 7].

Among the several techniques used for intrascleral fixation of IOL, the double-needle-flanged technique using ultrathin $30 \mathrm{G}$ needles and low-temperature cautery is gaining popularity [22]. However, some difficulties in intraocular manipulation, angled sclerotomy, and lens position adjustment without special guidance tools are experienced. Because of these factors, we often observe IOL dislocation or exposure of the flanged haptic, and it is sometimes difficult to reposition the IOL (Figures 1(a) and $1(\mathrm{~b})$ ).

Herein, we report a modified method for the intrascleral fixation of IOL, which can be performed extraocularly by navigation of the anatomical markers using two commonly used 27G blunted needles used for viscoelastic material injection and an ultrathin $30 \mathrm{G}$ needle. This technique requires fewer intraocular manipulations than the doubleneedle-flanged technique.

\section{Materials and Methods}

2.1. Participants. In this retrospective study, patients who underwent the modified method for intrascleral fixation of IOL between August 2017 and April 2019 were enrolled. 


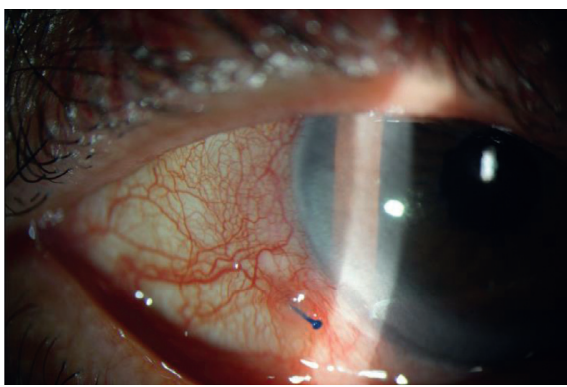

(a)

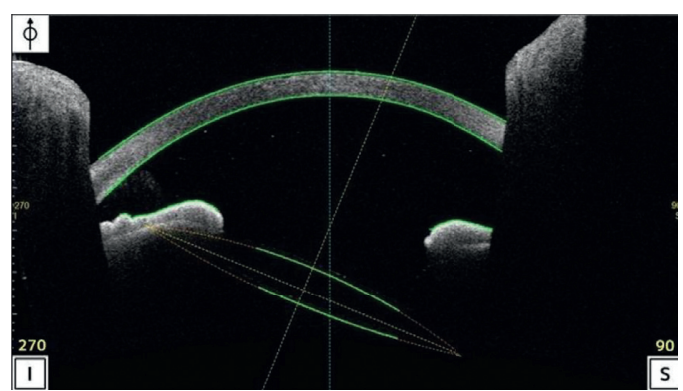

(b)

FIGURE 1: Complications after intrascleral fixation of intraocular lens by the double-needle-flanged technique. (a) Exposure of the flanged haptic and (b) intraocular lens dislocation.

Only those patients who had undergone postoperative follow-up examinations for 3 months were selected for this study. The procedures were performed according to the Declaration of Helsinki and were approved by the Osaka Red Cross Hospital ethics committee. Written informed consent was obtained from all patients after the nature and consequences of the study were described to them.

2.2. Intraocular Lens. We used a three-piece acrylic IOL (NX-70, Santen Pharmaceutical Co., Ltd, Osaka, Japan.) with an RXJ-70 injection system. The IOL was $13.2 \mathrm{~mm}$ long and had a $7 \mathrm{~mm}$ diameter optic. The haptics were composed of flexible polyvinylidene fluoride.

2.3. Surgical Procedure. A short version of the surgical procedure is shown in Supplementary Video 1.

Under perfusion, the conjunctiva was incised (Figure 2(a)), and a $3.0 \mathrm{~mm}$ corneoscleral incision was made at the 11-12 o'clock position using a slit knife. Half-depth radial scleral grooves were made at 3 and 9 o'clock positions (Figure 2(b)). Two more radial grooves were made $2 \mathrm{~mm}$ away from each initial groove. Between the two grooves, a half-depth scleral flap was created using a slit knife (Figure 2(c)). After vitrectomy was performed, sclerotomies were made under each scleral flap $2 \mathrm{~mm}$ from the limbs using a $20 \mathrm{G}$ microblade or $26 \mathrm{G}$ needle (Figure $2(\mathrm{~d})$ ). Two $27 \mathrm{G}$ blunted needles, used for viscoelastic material injection, were bent to connect each sclerotomy site and corneoscleral incision (Figures 2(e) and 2(f)). A bent 27G blunted needle prepared for the leading haptic was inserted into the eye via the sclerotomy site at the 3 o'clock position and was advanced through the surgical corneoscleral incision. The leading IOL haptic was inserted into this bent $27 \mathrm{G}$ blunted needle extraocularly (Figure $2(\mathrm{~g})$ ). The needle with the leading haptic was pushed into the eye, and the IOL was inserted while the needle sustained the IOL. The needle with the trailing IOL haptic was inserted into the eye through the sclerotomy site at the 9 o'clock position and was advanced through the corneoscleral incision along the optic surface of the IOL (Figure 2(h)). The needle was held with forceps in the left hand. The trailing IOL haptic was inserted into the needle with the needle holder in the right hand. Once the haptic was inserted, the needle was pulled back into the eye and advanced until the trailing haptic was extruded through the sclerotomy site. To avoid unwanted reversion, a small silicone piece was set at the tip of the trailing haptic (Figure 2(i)).

An ultrathin $30 \mathrm{G}$ needle was bent at about $4 \mathrm{~mm}$ from the tip to introduce each haptic into the scleral tunnels. The bent ultrathin $30 \mathrm{G}$ needle was inserted into the sclera parallel to the limbus and between the two grooves that had been made initially. The haptic was inserted into the lumen of the needle and buried into the scleral tunnel (Figure 2(j)). In case of a risk of dislocation, for example, with atopic dermatitis, the ends of haptics were flanged (Figure 2(k)). Finally, peripheral iridotomy was performed using the vitrectomy cutter and the alignment of the IOL was checked.

2.4. Astigmatism Induced by Intraocular Aberration. Vector subtraction was performed with refractometer and keratometer measurements to assess intraocular aberration 3 months after the surgery.

2.5. Intraocular Lens Tilt Measurements. The angle of tilt of the IOL was measured using swept-source optical coherence tomography (SS-1000 CASIA-2; Tomey Co., Nagoya, Japan) 3 months after surgery.

\section{Results}

Twenty eyes of 16 patients, which included four eyes with aphakia, six with IOL displacement, and ten with lens dislocation, were treated using this new intrascleral fixation technique. In all cases of IOL dislocation, the IOLs were replaced because they were single-piece acrylic IOLs. The ends of haptics were flanged in three cases (15\%). The mean patient age at the time of surgery was $67.2 \pm 14.3$ years (range, 38-85 years). Eleven eyes (55.0\%) were of men and 9 eyes $(45.0 \%)$ were of women. The mean axial length was $23.54 \pm 1.34 \mathrm{~mm}$. The patient characteristics are shown in Table 1.

A representative image of the anterior segment of the eye after the surgery is shown in Figure 2(1). The astigmatism induced by intraocular aberration was $-0.65 \pm 0.34 \mathrm{D}$. The mean (standard deviation (SD)) IOL tilt was $7.5 \pm 3.8^{\circ}$. The mean (SD) preoperative and postoperative corneal 


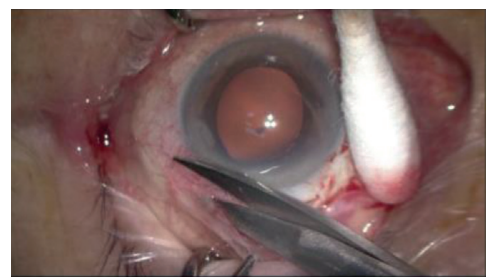

(a)

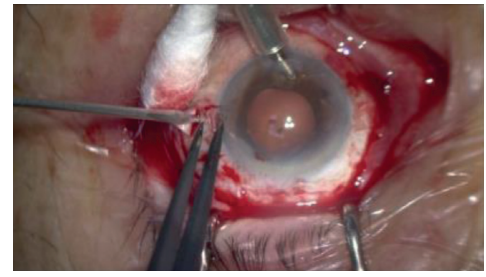

(d)

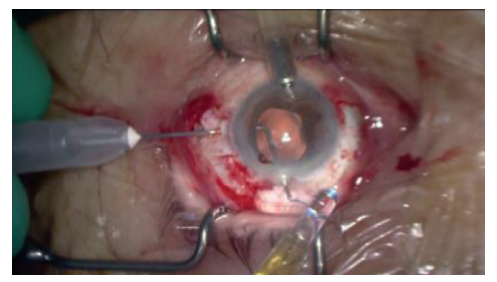

(g)

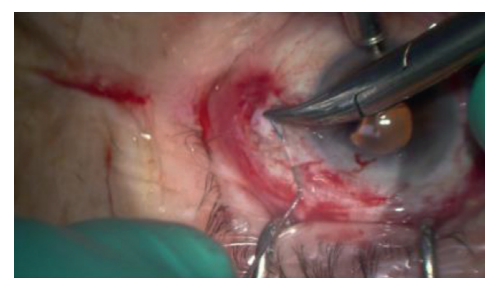

(j)

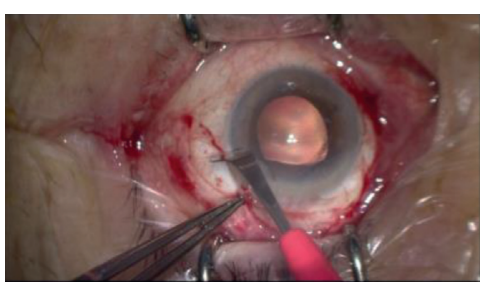

(b)

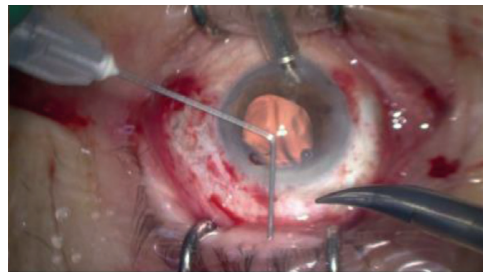

(e)

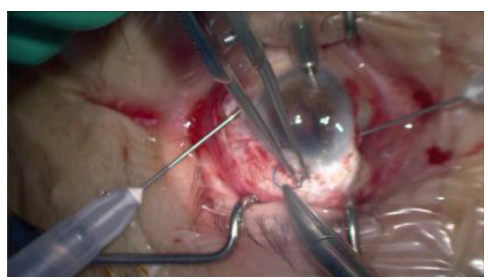

(h)

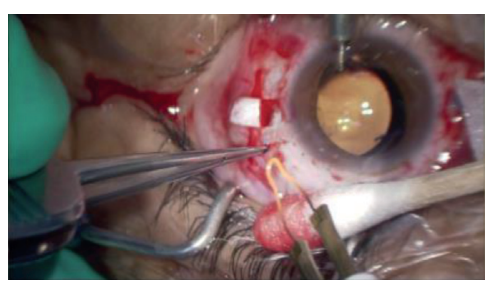

(k)

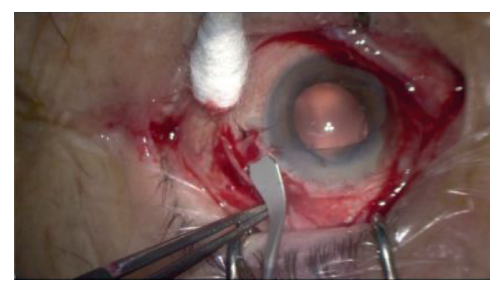

(c)

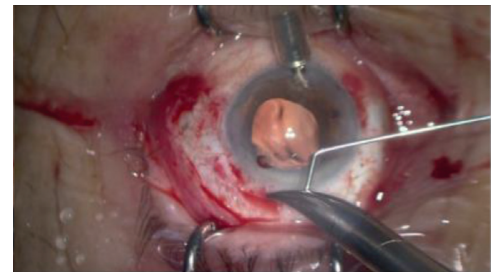

(f)

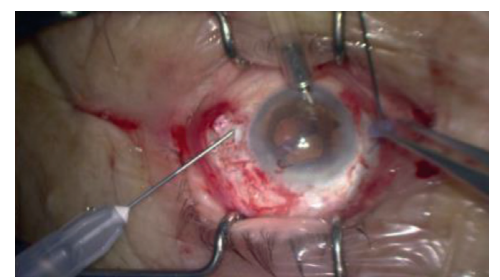

(i)

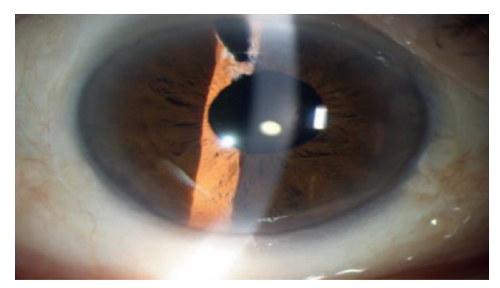

(1)

FIGURE 2: (a) Two-thirds superior conjunctival opening between 4 o'clock and 8 o'clock positions. (b) Half-depth radial scleral groove; (c) half-depth scleral flap; and (d) sclerotomy under each scleral flap using a 20G microblade; (e, f) bent 27G blunted needles ( $\mathrm{g}$, h) extruding haptics extraocularly; (i) locking of the trailing haptic with a small silicone piece; (j) burying the haptic into the scleral tunnel using a bent $30 \mathrm{G}$ ultrathin needle or $(\mathrm{k})$ flanged haptic in case of a risk of dislocation. (l) A slit-lamp photo of the anterior segment of the eye after the operation.

endothelial cell densities were $2471 \pm 666$ cells $/ \mathrm{mm}^{2}$ and $2006 \pm 632$ cells/mm [2], respectively. The mean (SD) corneal endothelial cell density loss 3 months postoperatively was $-11.0 \pm 13.8 \%$.

Complications included three cases of vitreous hemorrhage $(15.0 \%)$, two cases of postoperative hypotony $(<6 \mathrm{mmHg})(10.0 \%)$, and one case of intraoperative rhegmatogenous retinal detachment (5.0\%). All cases of vitreous hemorrhage disappeared within 2 weeks of surgery. Iris captures of the IOL were not observed in any case, and repositioning of the IOL for IOL tilt was also not performed in any case.

\section{Discussion}

The double-needle-flanged technique using 30G thin-wall needles appears quite simple and minimally invasive even without conjunctival incision. [22] However, some difficulties with intraocular manipulation, angled sclerotomy,
TABle 1: Patient characteristics.

\begin{tabular}{lc}
\hline Characteristics & Data \\
\hline Number of patients & 16 \\
Number of eyes & 20 \\
Age (years, range) & $67.2 \pm 14.3(38-85)$ \\
Sex (male/female) & $9 / 7$ \\
\hline \multicolumn{1}{c}{ Preoperative lens condition (number of eyes) } \\
Aphakia & 4 \\
IOL dislocation & 6 \\
Lens dislocation & 10 \\
& \\
IOL, intraocular lens.
\end{tabular}

and adjustment of the lens position are observed. It is not easy to insert the haptic of the IOL into the needle, especially for beginners, because of the narrow intraocular space, and it is also tricky to constantly shorten the haptic while making a flange. Furthermore, it is difficult to perform an angled 
TABLe 2: Comparison of surgical results with other techniques of intrascleral fixation of intraocular lens.

\begin{tabular}{|c|c|c|c|c|}
\hline Surgical results & Our study & $\begin{array}{c}\text { Yamane et al. [22] (double- } \\
\text { needle technique) }\end{array}$ & $\begin{array}{c}\text { Kelkar et al. [23] (modified } \\
\text { Yamane technique) }\end{array}$ & $\begin{array}{c}\text { Ishikawa et al. [26] (modified } \\
\text { Yamane technique) }\end{array}$ \\
\hline Number of eyes & 20 & 50 & 63 & 29 \\
\hline Intraocular lens model & $\begin{array}{l}\text { NX-70 } \\
\text { (Santen) }\end{array}$ & NX-70 (Santen) & Not available & NX-70 (Santen) \\
\hline Refractive difference (D) & $-0.65 \pm 0.34$ & $-0.41 \pm 0.98$ & -0.75 & $0.46 \pm 0.84$ \\
\hline $\begin{array}{l}\text { Astigmatism induced by } \\
\text { intraocular aberration }\end{array}$ & $-0.53 \pm 0.84$ & Not available & -1.3 & Not available \\
\hline IOL tilt $\left({ }^{\circ}\right)$ & $7.5 \pm 3.8$ & $3.83 \pm 2.69$ & Not available & Not available \\
\hline $\begin{array}{l}\text { Endothelial cell density loss } \\
\text { (\%) }\end{array}$ & $-11.0 \pm 13.8$ & Not available & Not available & $-17.2 \pm 18.3 \%$ \\
\hline
\end{tabular}

IOL, intraocular lens.

TABLE 3: Comparison of complications with other techniques of intrascleral and retropupillary fixation of intraocular lens.

\begin{tabular}{|c|c|c|c|c|c|}
\hline Complications & $\begin{array}{l}\text { Our } \\
\text { study }\end{array}$ & $\begin{array}{c}\text { Yamane et al. [22] } \\
\text { (double-needle } \\
\text { technique) }\end{array}$ & $\begin{array}{c}\text { Kelkar et al. [23] } \\
\text { (modified Yamane } \\
\text { technique) }\end{array}$ & $\begin{array}{c}\text { Ishikawa et al. [26] } \\
\text { (modified Yamane } \\
\text { technique) }\end{array}$ & $\begin{array}{c}\text { Mora et al. [7] } \\
\text { (retropupillary iris-claw } \\
\text { IOL fixation) }\end{array}$ \\
\hline Number of eyes & 20 & 100 & 63 & 29 & 32 \\
\hline $\begin{array}{l}\text { Temporary corneal } \\
\text { edema }\end{array}$ & $2(10)$ & $1(1)$ & 0 & & \\
\hline Vitreous hemorrhage & $3(15)$ & $5(5)$ & $2(3.2)$ & $3(10.3)$ & \\
\hline $\begin{array}{l}\text { Rhegmatogenous retinal } \\
\text { detachment }\end{array}$ & $1(5)$ & & & & $1(3)$ \\
\hline Temporary hypotony & $2(10)$ & $2(2)$ & $1(1.6)$ & $1(3.4)$ & \\
\hline $\begin{array}{l}\text { Temporary IOP } \\
\text { elevation }\end{array}$ & 0 & $2(2)$ & $2(3.2)$ & & $7(22)$ \\
\hline Iris capture & 0 & $8(100)$ & $1(1.6)$ & & \\
\hline Cystoid macular edema & 0 & $1(1)$ & $1(1.6)$ & & $8(25)$ \\
\hline
\end{tabular}

IOP, intraocular pressure.

sclerotomy through the conjunctiva using a $30 \mathrm{G}$ thin-wall needle, $2 \mathrm{~mm}$ from the limbs, at a good oblique angle, without any special marker (stabilizer). Owing to these factors, we often observe IOL dislocation or exposure of the flanged haptic, and it is sometimes difficult to reposition the IOL. Therefore, many surgeons have been trying to modify the technique for the better $[23,24,26]$. We considered methods to develop a fool proof technique for intrascleral fixation of IOL with fewer intraocular manipulations. Using the double-needle technique as a reference, we altered each step to develop a technique with commonly used instruments, in combination of the other published techniques.

Scleral flaps were created to bury both the sclerotomy site and the haptics exposed between the sclerotomy site and the tunnel $[9,14]$. Sclerotomies were made with a $20 \mathrm{G} \mathrm{MVR}$ perpendicularly to obtain sufficient space for the adjustment of the haptic alignment and to perform consistently with only anatomical markers [25]. The haptics were extruded using long $27 \mathrm{G}$ blunted needles to avoid restricted intraocular manipulations, and 30G ultrathin needles were used as a guide for the insertion of the haptics into the right-sized scleral tunnels [16]. Our modified technique is performed extraocularly under the navigation of anatomical markers and with commonly used instruments without specialized devices.
Vertically angled sclerotomies can be performed using a $26 \mathrm{G}$ needle. However, the tightness causes difficulty in alignment of the IOL. Matsumura et al. [25] reported that a smaller sclerotomy incision size for intrascleral IOL fixation was associated with greater IOL tilt and IOL astigmatism after surgery.

The scleral tunnels can be made without conjunctival opening and half-depth scleral flaps using two ultrathin $30 \mathrm{G}$ needles [20]. In this case, the first 30G needle was inserted into the sclera from the sclerotomy site to form a scleral tunnel, and the second needle was used to push the first needle out.

On comparing the intraocular and extraocular operation techniques, the extraocular operation can be performed with greater flexibility and is relatively easier. In addition, even under restrictions, the risk of IOL falling into the vitreous cavity is reduced if the operation is performed outside the eye. We have developed this IOL intrascleral fixation technique based on the observable benefits of sutured scleral fixation of IOL and of double-needle-flanged technique.

The ends of haptics were flanged in three patients (15\%): one with atopic dermatitis and two others who played tennis and golf frequently. To flange haptics, the haptics were inserted into the guiding needle beyond the scleral tunnel. Once the needle was removed, the end of the haptics appeared on the sclera. After the haptics were flanged, the 
end was pushed back into the scleral tunnel. This additional step is not complicated; nonetheless, in our experience, it is not required for the majority of cases $[16,20]$.

Surgical outcomes were comparable to those of previously described techniques of intrascleral fixation of IOL [22, 23, 26] (Table 2). Our study did not have a control group, but the IOL position looked acceptable even when our technique was performed using anatomical markers.

Postoperative complications seem similar between our technique and the previously described techniques of intrascleral and retropupillary fixation of $\operatorname{IOL}[7,22,23,26]$ (Table 3). Intraoperative rhegmatogenous retinal detachment was seen in one case (5\%) treated with our method. The detachment occurred when posterior vitreous detachment was induced during vitrectomy before IOL fixation; therefore, we consider this to be unrelated to our method.

Although our technique requires conjunctival opening, it can be performed in any operation room without extra instruments. We believe that our technique is easy to try for beginners. After some experience with this technique, surgeons can extend their technique without scleral flaps and conjunctival incision (Supplementary Video 2).

There are several limitations to this study. It was a retrospective and single-arm study, and patients were selected arbitrarily instead of consecutively. Therefore, further research is warranted to validate our findings.

\section{Conclusions}

We have developed a new technique for intrascleral IOL fixation that can be performed extraocularly by navigation of the anatomical markers in combination with established techniques. Surgical outcome and postoperative complications were comparable to those of previously described techniques of intrascleral fixation of IOL. Our technique is easy to attempt because it can be performed in any operation room without extra instruments.

\section{Data Availability}

The data used to support the findings of this study are available from the corresponding author upon request.

\section{Additional Points}

Trial registration: UMIN, UMIN000044350, retrospectively registered (https://upload.umin.ac.jp/cgi-bin/ctr/ ctr_view_reg.cgi?recptno=R000048780).

\section{Disclosure}

The data were presented at the 43rd Annual Meeting of the Japanese Society of Ophthalmic Surgery, Tokyo, Japan, February 2020; 2020 ASCRS Virtual Annual Meeting, May 2020; and 38th Congress of the ESCRS, October 2020.

\section{Conflicts of Interest}

MA is a consultant at Kowa Co., Ltd. KM and YI have no conflicts of interest.

\section{Acknowledgments}

The authors would like to thank Editage (http://www. editage.com) for editing and reviewing this manuscript for English language.

\section{Supplementary Materials}

Video S1: this video demonstrates a shorter version of the original technique. Video S2: this video demonstrates a modified version of the technique, without a scleral flap and conjunctival incision. (Supplementary Materials)

\section{References}

[1] Z. Biro, "Results and complications of secondary intraocular lens implantation," Journal of Cataract and Refractive Surgery, vol. 19, no. 1, pp. 64-67, 1993.

[2] J. E. Downing, "Ten-year follow up comparing anterior and posterior chamber intraocular lens implants," Ophthalmic Surgery, Lasers and Imaging Retina, vol. 23, no. 5, pp. 308-315, 1992.

[3] C. Evereklioglu, H. Er, N. A. Bekir, M. Borazan, and F. Zorlu, "Comparison of secondary implantation of flexible open-loop anterior chamber and scleral-fixated posterior chamber intraocular lenses," Journal of Cataract and Refractive Surgery, vol. 29, no. 2, pp. 301-308, 2003.

[4] L. Drolsum, "Long-term follow-up of secondary flexible, open-loop, anterior chamber intraocular lenses," Journal of Cataract and Refractive Surgery, vol. 29, no. 3, pp. 498-503, 2003.

[5] R. Frisina, E. Pilotto, L. Tozzi, R. Parrozzani, and E. Midena, "A new technique of needle-guided retropupillary fixation of iris-claw intraocular lens," Journal of Cataract and Refractive Surgery, vol. 45, no. 3, pp. 267-271, 2019.

[6] A. M. Shuaib, Y. El Sayed, A. Kamal, Z. El Sanabary, and H. Elhilali, "Transscleral sutureless intraocular lens versus retropupillary iris-claw lens fixation for paediatric aphakia without capsular support: a randomized study," Acta Ophthalmologica, vol. 97, pp. e850-859, 2019.

[7] P. Mora, G. Calzetti, S. Favilla et al., "Comparative analysis of the safety and functional outcomes of anterior versus retropupillary iris-claw IOL fixation," Journal of Ophthalmology, vol. 2018, Article ID 8463569, 8 pages, 2018.

[8] S. G. B. Gabor and M. M. Pavlidis, "Sutureless intrascleral posterior chamber intraocular lens fixation," Journal of Cataract and Refractive Surgery, vol. 33, no. 11, pp. 1851-1854, 2007.

[9] A. Agarwal, D. A. Kumar, S. Jacob, C. Baid, A. Agarwal, and S. Srinivasan, "Fibrin glue-assisted sutureless posterior chamber intraocular lens implantation in eyes with deficient posterior capsules," Journal of Cataract and Refractive Surgery, vol. 34, no. 9, pp. 1433-1438, 2008.

[10] I. Rodríguez-Agirretxe, A. Acera-Osa, and M. Ubeda-Erviti, "Needle-guided intrascleral fixation of posterior chamber intraocular lens for aphakia correction," Journal of Cataract \& Refractive Surgery, vol. 35, pp. 2051-2053, 2009.

[11] M. Saleh, A. Heitz, T. Bourcier et al., "Sutureless intrascleral intraocular lens implantation after ocular trauma," Journal of Cataract and Refractive Surgery, vol. 39, no. 1, pp. 81-86, 2013.

[12] L. López-Guajardo and J. Benítez-Herreros, "Sulcus fixation of an intraocular lens by means of haptic insertions in scleral 
tunnels: results at one year," Archivos de la Sociedad Espanola de Oftalmologia, vol. 85, pp. 278-280, 2010.

[13] S. Yamane, M. Inoue, A. Arakawa, and K. Kadonosono, "Sutureless 27-gauge needle-guided intrascleral intraocular lens implantation with lamellar scleral dissection," Ophthalmology, vol. 121, no. 1, pp. 61-66, 2014.

[14] T. Ohta, H. Toshida, and A. Murakami, "Simplified and safe method of sutureless intrascleral posterior chamber intraocular lens fixation: Y-fixation technique," Journal of Cataract and Refractive Surgery, vol. 40, no. 1, pp. 2-7, 2014.

[15] M. Akimoto, H. Taguchi, and T. Takahashi, "Using catheter needles to deliver an intraocular lens for intrascleral fixation," Journal of Cataract and Refractive Surgery, vol. 40, no. 2, pp. 179-183, 2014.

[16] M. Akimoto, H. Taguchi, K. Takayama, S. Nakagawa, and K. Hiroi, "Intrascleral fixation technique using catheter needles and 30-gauge ultrathin needles: lock-and-lead technique," Journal of Cataract and Refractive Surgery, vol. 41, no. 2, pp. 257-261, 2015.

[17] Y. Totan and R. Karadag, "Trocar-assisted sutureless intrascleral posterior chamber foldable intra-ocular lens fixation," Eye, vol. 26, no. 6, pp. 788-791, 2012.

[18] S. Prasad, "Transconjunctival sutureless intrascleral fixation of posterior chamber intraocular lens (PC IOL)," in Proceedings of the 30th Annual Meeting of the American Society of Retina Specialists, Las Vegas, NV, USA, August 2012.

[19] S. Yamane, M. Inoue, A. Arakawa, and K. Kadonosono, "Transconjunctival needle-guided intrascleral intraocular lens fixation," in Proceedings of the 2014 World Ophthalmology Congress, Tokyo, Japan, April 2014.

[20] K. Takayama, M. Akimoto, H. Taguchi, S. Nakagawa, and K. Hiroi, "Transconjunctival sutureless intrascleral intraocular lens fixation using intrascleral tunnels guided with catheter and 30-gauge needles," British Journal of Ophthalmology, vol. 99, no. 11, pp. 1457-1459, 2015.

[21] I. Maruko, H. Koizumi, A. Kogure-Katakura, and T. Iida, "Extraocular technique of intrascleral intraocular lens fixation using a pair of the shaft-bended 27-gauge needles," Retina, vol. 37, no. 1, pp. 191-193, 2017.

[22] S. Yamane, S. Sato, M. Maruyama-Inoue, and K. Kadonosono, "Flanged intrascleral intraocular lens fixation with doubleneedle technique," Ophthalmology, vol. 124, no. 8, pp. 1136-1142, 2017.

[23] A. Kelkar, R. Fogla, J. Kelkar, A. Kothari, H. Mehta, and W. Amoaku, "Sutureless 27-gauge needle-assisted transconjunctival intrascleral intraocular lens fixation: initial experience," Indian Journal of Ophthalmology, vol. 65, no. 12, pp. 1450-1453, 2017.

[24] K. Yavuzer and Y. Evcimen, "Sutureless transconjunctival intrascleral intraocular lens fixation: the modified Yamane technique," Arquivos Brasileiros de Oftalmologia, vol. 82, pp. 389-393, 2019.

[25] T. Matsumura, Y. Takamura, J. Makita, A. Kobori, and M. Inatani, "Influence of sclerotomy size on intraocular lens tilt after intrascleral intraocular lens fixation," Journal of Cataract and Refractive Surgery, vol. 45, no. 10, pp. 1446-1451, 2019.

[26] H. Ishikawa, H. Fukuyama, Y. Komuku, T. Araki, and F. Gomi, "Flanged intraocular lens fixation via 27-gauge trocars using a double-needle technique decreases surgical wounds without losing its therapeutic effect," Acta Ophthalmologica, vol. 98, pp. e499-503, 2020. 